\title{
Avaliação da microinfiltração em cavidades classe II utilizando as associações ionômero fotopolimerizável - resina composta e amálgama - resina composta
}

\author{
André Luiz Araújo Mello* \\ André Vinicius Moreira da Cunha* \\ Ewerton Nocchi Conceiçăo**
}

\begin{abstract}
RESUMO
Os autores avaliaram in vitrro a microinfiltraçăo nas associaçōes ionômero fotopolimerizável-resina composta $\Theta$ amálgama-resina composta em cavidades classe II com a margem gengival abaixo da junção amelocementária comparativamente a restauraçōes de resina composta.
\end{abstract}

\section{SUMMARY}

The authors evaluated in vitro microleakage of class II combined amalgam - composite and light-cured glass-ionomer composite restorations below the cementoenamel junction.

\section{Introdução}

A resina composta tem sido cada vez mais utilizada nas restauraçōes de dentes posteriores, principalmente por suas propriedades estéticas. Ela promove um bom selamento nas superfícies de esmalte previamente atacadas com ácido fosfórico (Buonocore, 1955). No entanto, o selamento não é tão eficaz nas zonas de dentina e cemento pelas particularidades desses tecidos, causando faIhas na interface dentina-resina ou cemento-resina, o que propicia uma posterior microinfiltração pelo ingresso de fluidos e bactérias (19). A microinfiltraçăo pode gerar problemas como cárie secundária $(13,16)$ e inflamação pulpar (4).

Alguns autores, como Zidan et al. (28), defendem que a aplicação da técnica dos três incrementos na restauração da caixa proximal com resina composta aumenta significativamente o selamento em dentina e cemento.

Ainda na tentativa de solucionar esse problema, vários trabalhos têm proposto o uso de outros materiais associados à resina composta. Ei- delman et al. (08) sugeriram a combinação amálgama-resina em cavidades classe II e mostraram que houve uma diminuição na microinfiltração quando comparada com restauração de resina composta isoladamente. Garcia-Godoy \& Malone (10) usaram o ionômero de vidro com base de restauração de resina em cavidades classe $\mathrm{V}$ e afirmaram que esse material, apesar de diminuir, não foi capaz de eliminar totalmente a microinfiltração na parede gengival.

O objetivo dessa pesquisa foi avaliar a microinfiltração na parede gengival de cavidades classe II restauradas com associação amálgama-resina e ionômero fotopolimerizável-resina e compará-las com cavidades em que foram feitas restauraçōes somente com resina composta.

\section{Materiais e Métodos}

Trinta molares permanentes humanos extraídos foram usados na pesquisa. Em cada um desses dentes foi preparada uma cavidade classe II em alta rotação com uma ponta diamantada KG SORENSEN número 4103 sob refrigeração d'água.

As cavidades preparadas tinham a parede pulpar com uma profundidade de $3 \mathrm{~mm}$ com uma abertura da caixa oclusal de aproximadamente $1 \mathrm{~mm}$ no sentido vestíbulo-lingual. Já a caixa proximal tinha a parede gengival $1 \mathrm{~mm}$ abaixo da junçăo amelocementária, $2 \mathrm{~mm}$ de espessura no sentido vestíbulo-lingual e $1 \mathrm{~mm}$ de espessura no sentido mésio-distal.

Após a confecção dos preparos foi feita a profilaxia dos dentes com pedra-pomes e taça de borracha em baixa-rotação.

Para a confecção das restauraçőes os dentes foram divididos em 3 grupos de 10 dentes cada conforme os materiais restauradores utilizados (Tabela 1).

Nos dez dentes selecionados para 0 grupo 1 (controle) foi feito ataque ácido (ácido fosfórico a $37 \%)$ em toda margem de esmalte da cavidade por 60 segundos e lavagem com água pelo mesmo tempo. Os dentes foram secos,

\footnotetext{
* Monitor da Disciplina de Materiais Dentários FO/UFRGS

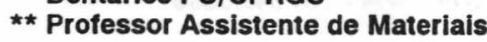
Dentários FO/UFRGS
}

\begin{tabular}{l|l} 
R. Fac. Odontol. & Porto Alegre
\end{tabular}
N. 2

V. 33 
TABELA 1

Materlais restauradores utilizados

\begin{tabular}{|c|c|c|}
\hline GRUPO & MATERIAL & MARCA/FABRICANTE \\
\hline \multirow[t]{2}{*}{1} & & $\begin{array}{l}\text { Prisma Universal Bond } 3 \\
\text { (Dentsply) }\end{array}$ \\
\hline & Resina fotopolimerizável & Prisma APH (Dentsply) \\
\hline \multirow[t]{2}{*}{2} & $\begin{array}{l}\text { lonômero de vidro fotopolimerizável } \\
\text { Adesivo }\end{array}$ & $\begin{array}{l}\text { Vitrebond (3M) } \\
\text { Prisma Universal Bond } 3 \\
\text { (Dentsply) }\end{array}$ \\
\hline & Resina fotopolimerizável & Prisma APH (Dentsply) \\
\hline \multirow[t]{2}{*}{3} & $\begin{array}{l}\text { Amálgama } \\
\text { Adesivo }\end{array}$ & $\begin{array}{l}\text { True Dentalloy II (SS White) } \\
\text { Prisma Universal Bond } 3 \\
\text { (Dentsply) }\end{array}$ \\
\hline & Resina fotopolimerizável & Prisma APH (Dentsply) \\
\hline
\end{tabular}

receberam aplicação de primer (Prisma Universal Bond 3 ) na dentina por 30 segundos e posteriormente um jato de ar. Foi, então, aplicado o adesivo (Prisma Universal Bond 3) e fotopolimerizado por 20 segundos.

Seguiu-se a colocaçăo de resina (Prisma APH) - 3 incrementos na caixa proximal (18) e 2 incrementos na oclusal - com auxílio de uma matriz transparente e de um porta-matriz TOFFLEMIRE. $O$ incremento gengival da caixa proximal foi fotopolimerizado com ajuda de uma cunha refletiva (17) por 120 segundos, enquanto os outros incrementos estiveram submetidos à luz por 60 segundos.

Na restauração do grupo 2 foi usado o cimento de ionômero de vidro fotopolimerizável VITREBOND na parede gengival da caixa proximal indo até o ângulo cavo-superficial (25) e com uma altura de, aproximadamente, $1.5 \mathrm{~mm}$, chegando acima da junção amelo-cementária. A aplicação foi com um porta-Dycal e com a utilização de uma matriz de poliéster e cunha refletiva. O VITREBOND foi manipulado conforme instruções do fabricante e polimerizado por 60 segundos através da cunha e mais 30 segundos por oclusal. Após, realizou-se o ataque ácido apenas do esmalte, năo o colocando sobre o ionômero (10). Então foi aplicado o adesivo e fotopolimerizado por 20 segundos. A sequência para a confecção das restaurações foi a mesma utilizada para 0 grupo $1 \mathrm{com}$ exceçăo da colocaçăo de apenas 2 in- crementos de resina na caixa proximal.

No grupo 3 foi colocado amálgama de prata com alto teor em cobre (True Dentalloy II) na parede gengival, numa altura de cerca de $1.5 \mathrm{~mm}$, também ficando um pouco além da junçăo amelo-cementária. Para a confecção das restauraçōes usou-se porta-matriz TOFFLEMIRE e matriz de aço. A seguir repetiu-se os procedimentos no grupo 2 .

Logo após a cenfecção de cada grupo de restauraçōes foi dado acabamento com pontas diamantadas ultra-finas da série prateada (KG SORENSEN) e com tiras de lixa (VIKING).

Posteriormente, os dentes foram submetidos a 100 ciclos térmicos, sendo cada ciclo composto de um banho de 1 minuto a $5^{\circ} \mathrm{C}\left(+/-5^{\circ} \mathrm{C}\right), 1$ minuto a $37^{\circ} \mathrm{C}\left(+/-5^{\circ} \mathrm{C}\right)$ e 1 minuto a $60^{\circ} \mathrm{C}\left(+/-5^{\circ} \mathrm{C}\right)$.

Os dentes foram então cobertos com esmalte de unha e uma camada de cera número 7 , deixando livre apenas a restauraçăo e uma faixa de $1 \mathrm{~mm}$ ao redor dela. Em seguida, os dentes foram imersos num corante (azul de metileno a $0.5 \%$ ) e mantidos durante 72 horas numa estufa a $37^{\circ} \mathrm{C}$.

Após a remoção do corante, os dentes foram lavados e seccionados no sentido mésio-distal com um disco de diamante de dupla iace em baixa rotação. As superfícies foram polidas com lixas abrasivas NORTON (números 320,500 e 600, respecti- vamente) e então observados em uma lupa estereoscópica WILD com um aumento de 25 vezes. A avaliaçăo obedeceu os seguintes critérios (fig. 1).

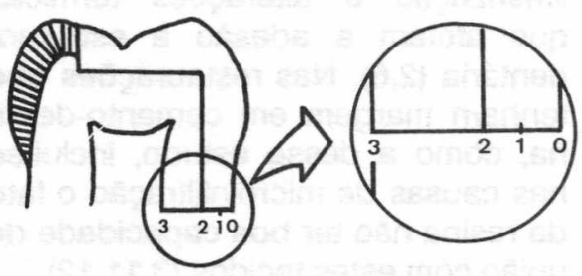

0 - ausência de penetraçăo do corante

1 - Corante penetrou entre dente e restauraçăo ao longo da parede gengival até no máximo a metade de sua extensăo

2 - corante penetrou em toda extensăo da parede gengival

3 - corante penetrou através da parede gengival do praparo e chegou à câmara pulpar

O teste estatístico de Kruskal-Wallis foi aplicado aos resultados a um nível de significância de 1 e $5 \%$.

\section{Resultados}

Todos os dentes restaurados apresentaram infiltraçăo na margem cervical das restauraçōes (Tabela 2).

TABELA 2

Classificação das amostras segundo os níveis de infiltraçāo marginal

\begin{tabular}{ccccc}
\hline GRUPOS & 0 & 1 & 2 & 3 \\
\hline 1 & - & - & - & 10 \\
\hline 2 & - & - & 2 & 8 \\
\hline 3 & - & 4 & - & 6 \\
\hline
\end{tabular}

Comparando-se os escores de microinfiltraçăo, através do teste de Kruskal-Wallis ao nível de $5 \%$ e $1 \%$, verificamos que não houve diferença estatisticamente significante entre os 3 grupos-teste.

\section{Discussão}

Em nosso trabalho nenhum dos materiais utilizados, amálgama, resina e ionômero, foi capaz de eliminar totalmente a microinfiltraçăo na pa-
R. Fac. Odontol.

Porto Alegre

V. 33

N. 2

p.2-5

DEZEMBRO

1992 
rede gengival (cemento-dentina) como também afirmam outros pesquisadores $(8,9,10,11,12,14,20,24)$.

As possíveis causas de microinfiltração em restaurações de resina composta incluem contração de polimerização e alteraçōes térmicas que afetam a adesăo à estrutura dentária $(2,6)$. Nas restaurações que tenham margem em cemento-dentina, como a desse estudo, inclui-se nas causas de microinfiltraçăo o fato da resina não ter boa capacidade de união com estes tecidos $(3,11,12)$.

$O$ ionômero de vidro por apresentar adesão aos tecidos dentários $(3,7,10,12,22)$, biocompatibilidade $(12,22)$ e capacidade de liberação de flúor $(7,10,12,22,27)$, tem sido utilizado como material de base, especialmente em restauraçóes de resina composta. As vantagens dos ionômeros fotopolimerizáveis, como a maior facilidade de manipulação, redução do tempo de presa e maior resistência de união à dentina (22), explicam maior interesse por esse material em relação aos convencionais. Nessa pesquisa usamos o ionômero de vidro fotoativado, pois supomos que essa alta resistência de uniăo poderia minimizar o problema da microinfiltração, o que não foi comprovado pelos resultados, mostrando que a contração de polimerização inerente a esse material e a união química com a resina composta pode provocar o surgimento de espaços na interface dente-restauração permitindo a penetração do corante. No entanto, a liberação de flúor pode minimizar o risco do surgimento de cáries secundárias, apesar de não selar completamente a interface dente-restauração $(10,12)$.

A união entre ionômero fotopolimerizável e resina foi excelente, já que não houve penetração do corante entre esses dois materiais. Isso ocorreu, provavelmente, pela uniāo química que existe entre o ionômero fotoativado e a resina composta, o que já não acontece com o ionômero convencional (23). O amálgama foi o material que teve algumas amostras apresentando um nível de infiltração menos severo (nível 1), mas apesar disso năo houve diferença estatística significante para os outros grupos. Não usamos verniz pois não há redução total da infiltração quando usamos esse material sob restauraçōes de amálgama, especialmente na parede gengival (20). O amálgama isoldamente não foi capaz de evitar a microinfiltraçăo, pois demora certo período de tempo para que se forme seus produtos de corrosão, especialmente em ligas com alto teor em cobre $(1,9)$, além de apresentar uma diferença de coeficiente de expansão térmica com relação às estruturas dentárias.

A exemplo da interface ionômeroresina, a interface amálgama-resina não apresentou infiltração do corante. Isso ocorre porque o adesivo penetra nas rugosidades e irregularidades da superfície do amálgama, criando uma união mecânica com a resina (21). Não realizamos ataque ácido sobre o amálgama, pois isso representa a ocorrência de uma menor microinfiltração na interface amálgama-resina (14). A explicaçăo para tal fato pode ser a dificuldade de remover completamente o ácido em forma de gel da superfície rugosa do amálgama, além de que o ácido dificulta uma melhor adesão entre o amálgama e a resina (14).

Outra possibilidade restauradora é, no futuro, a comprovação da eficiência da utilização de adesivos associados a restaurações de amálgama (amálgama-adesivo)(26). Do mesmo modo, é necessária a comprovação da eficiência do selamento marginal dos novos sistemas adesivos para resina composta que incluem um ataque ácido à dentina e esmalte simultaneamente (15).

Então, apesar de nenhum dos materiais selar completamente a interface dente-restauração, o amálgama pode ser uma boa opção associado à restauração classe II de resina composta. Isto em função de sua facilidade de manipulação, do baixo custo e de permitir a condensação e a consequente adaptação na caixa proximal, além do fato de não ter apresentado infiltração na interface com a resina. O lonômero fotopoli- merizável também pode ser indicado pela sua capacidade de liberar flúor e facilidade de manipulação quando comparado com o ionômero convencional.

\section{Conclusões}

1. A infiltração marginal na parede cervical dos dentes restaurados não foi eliminada totalmente por nenhum dos materiais utilizados.

2. Năo houve diferença estatística significante ao nível de $1 \%$ e $5 \%$ quanto à penetração do corante na parede cervical entre os grupos testados.

\section{REFERÊNCIAS BIBLIOGRÁFICAS}

01. ANDREWS, J.T.; HEMBREE, J.H. Marginal leakage of amalgam alloys with high content of cooper: a laboratory study. Oper Dent, Seatltle, v.5, p.7-10, 1980.

02. ASMUSSEN, E. The effect of temperature changes on adaptation of resin fillings. Acta Odontol Scand, Oslo, v.32, p.161-171, 1974.

03. BRACKETT, W.W.; ROBINSON, P.B. Composite resin and glass-ionomer cement: current status for use in cervical restorations. Quint Int, Berlin, v.21, p.445-447, 1990.

04. BROWNE, R.M.; TOBIAS, R.S. Microbial microleakage and pulpal inflammation: a review. Endod Dent Traumatol, Copenhagen, v.2, p.177-183, 1986.

05. BUONOCORE, M.G. A simple method of increasing the adhesion of acrylic filling materials to enamel surfaces. J Dent Res, Washington, v.34, p.849-853, 1955.

06. CRIM, G.A.; GARCIA-GODOY, F. Microleakage: effect of cycling and storage duration. J Prosthet Dent, St. Louis, v.57, p.574-576, 1987.

07. CRIM, G.A.; SHAY, J.S. Microleakage pattern of a resinveneered glass-ionomer cavity liner. J Prosthet Dent, St. Louis, v.58, p.273-276, 1987.

08. EIDELMAN, E.; HOLAN, G.; TANZER-SARETH, S. et al. An evaluation of marginal leakage of class 2 combined amalgamcomposite restorations. Oper Dent, Seattle, v.15, p.141-148, 1990.

09. FITCHIE, J.G.; REEVES, G.W.; SCARBROUGH, A.R. et al. Microleakage of a new cavity varnish with a high-copper spherical amalgam alloy. Oper Dent, Seattle, v.15, p.136-140, 1990.

10. GARCIA-GODOY, F.; MALONE, W.F.P. Microleakage of posterior composite resins using glass-ionomer cement bases. Quint Int, Berlin, v.19, n.1, p.13-17, 1988.

11. GORDON, M.; PLASSCHAERT, A.J.M.; SAIKU, J.M. et al. Microleakage of posterior composite resins materials and an experimental urethane resiorative material, tested in vitro above and below the cementoenamel junction. Quint Int, Berlin, v.17, n.1, p.11-15, 1986. 
12. GORDON, M.; PLASSCHAERT, A.J.M.; SOELBERG, K.B. et al. Microleakage of four composite resins over a glass-ionomer cement base in class $V$ restorartions. Quint Int, Berlin, v.12, p.817-820, 1985.

13. GRIEVE, A.R. The occorrence of secondary caries-like lesions in vitro. The effect of a fluoride cavity liner and a cavity varnish. $\mathrm{Br}$ Dent J, London, v.134, p.530-536, 1973.

14. HADAVI, F.; HEY, J.H.; AMBROSE, E.R. Assessing microleakage at the junction between amalgam and composite resin: A new method in vitro. Oper Dent, Seattle, v.16, p.6-12, 1991.

15. KANKA III, J. Dental adesion and All Bond system. J Esthetic Dent, v.3, n.4, p.129-132, 1991.

16. LUNDIN, S.A.; NOREN, J.G.; WARFVINGE, J. Marginal bacterial leakage and pulp reactions in class II composite resin restorations in vivo. Swed Dent J, Jonkoping, v.14, p.185-192, 1990.

17. LUTZ, F.; KREJCl, I.; LUESCHER, B ot al. Improved proximal margin adaptation of class II composite resin restorations by use of light-reflecting wedges. Quint Int, Berlin, v.17, n.10, p.659-668, 1986.
18. LUTZ, F.; KREJCI, I.; OLDENBURG, T.R. Elimination of polimerization stresses at the margins of posterior composite resins restorations: A new restorative technique. Oper Dent, Seattle, v.17, n.12, p.777-784, 1986.

19. KIDD, E.A. Microleakage: A review. J Dent, Guildford, v.4, n.5, p.199-206, 1976.

20. McCOMB, D.; BEN-AMAR, A.; BROWN, J. Sealing efficacy of therapeutic varnishes used with silver amalgam restorations. Oper Dent, Seattle, v.15, p.122-128, 1990.

21. MERTZ-FAIRHURST, E.J.; NEWCOMER, A.P. Interface gap at amalgam margins. Dent Mat, v.4, n.3, p.122-128, 1988.

22. MITRA, S.B. Adhesion to dentin and phisical to properties of a light-cured glassionomer liner/base. J Dent Res, Washington, v.70, n.1, p.72-74, 1991.

23. PACHECO, J.F.M.; CONCEIÇĀO, E.N.; SUFFERT, L.W. Associaçāo ionômero de vidro-resina composta: influência na infiltraçāo marginal de restauraçōes classe V. R Fac Odontol, Porto Alegre, v.33, n.1, p.22-25, 1992.
24. PRATI, C.; MONTANARI, G. Comparative microleakage study between the sandwich and conventional three-increment tecniques. Quint Int, Berlin, v.20, n.8, p.587-594, 1989.

25. RETIEF, D.H.; McCAGHREN, R.A.; RUSSEL, C.N. Microleakage of Vitrebond/p-50 class II restorations. Am J. Dent, San Antonio, v.5, n.3, p.130-132, 1992.

26. STANINEC, M.; HOLT, M. Bonding of amalgam to tooth structure: tensil adesion and microleakage tests. J Prosthet Dent, St. Louis, v.59, n.4, p.397-402, 1988.

27. SWARTZ, M.L.; PHILLIPS, R.W.; CLARK, H.E. Long Term $F$ release from glass ionomer cements. J Dent Res, Washington, v.63, n.2, p.158-160, 1984.

28. ZIDAN, O.; GOTTES-MARIN, O.; TSUCHIYA, T.A. Comparative study of the effects of dentinal bonding agents and application techniques on marginal gaps in class $V$ cavities. J Dent Res, Washington, v.66, p.716-721, 1987. 